\title{
Recurrent neural tube defects, risk factors and vitamins
}

\author{
J WILD, A P READ, S SHEPPARD, M J SELLER, R W SMITHELLS, \\ N C NEVIN, C J SCHORAH, D W FIELDING, S WALKER, * AND R HARRIS
}

Departments of Paediatrics and Child Health and Chemical Pathology, University of Leeds, Department of Medical Genetics, University of Manchester, Paediatric Research Unit, Guy's Hospital, London, Department of Medical Genetics, Queen's University of Belfast, Department of Paediatrics, The Countess of Chester Hospital, Chester, and Cytogenetics Unit, Royal Liverpool Hospital

SUMMARY Data from our trial of periconceptional vitamin supplementation for the prevention of neural tube defects have been analysed to assess the influence of various factors on recurrence rates of neural tube defect. Our data suggest that the risk of recurrence of neural tube defect is influenced by the number of previous neural tube defects, area of residence, immediately prior miscarriage, and interpregnancy interval. None of these factors, however, contributed any significant differential risk between supplemented and unsupplemented mothers. Hence we conclude that the highly significant difference in recurrence rates of neural tube defect between supplemented and unsupplemented mothers was due to vitamin supplementation.

We have reported a highly significant reduction in the recurrence rate of neural tube defect in mothers given a periconceptional multivitamin supplement (Pregnavite Forte F) when compared with unsupplemented mothers recorded by the same centres over the same period.' As our study was not randomised several workers ${ }^{2-5}$ have suggested that supplemented and unsupplemented mothers had different prior risks of recurrence of neural tube defect and that this, rather than any effect of the vitamins, could be responsible for the observed difference in recurrence rates. In this report supplemented mothers are those referred to as fully supplemented in previous reports - that is, they have taken Pregnavite Forte F from not less than 28 days before conception until the time of the second missed menstrual period.

We report here the distribution in our supplemented and unsupplemented mothers of factors that are known or suspected to modify the risk of occurrence of neural tube defect. Factors affecting the occurrence risk would be expected also to modify the recurrence risk, although there are few direct data to confirm this. We have considered the following factors:

(1) Number of previous neural tube defects. All

\footnotetext{
*Died 5 July 1985.
}

mothers, whether supplemented or unsupplemented, had had at least one previous neural tube defect, but it is known that the rate of recurrence increases in relation to the number of previous neural tube defects. Two or more previous neural tube defects are therefore regarded as indicative of 'high risk'.

(2) Social class. A social class gradient has been recognised for many years, the birth prevalence of neural tube defect being lowest in social class I and highest in social class V. One study has reported a similar gradient in recurrence rates. ${ }^{\text {F }}$ For purposes of analysis, classes I, II, and III non-manual are regarded as 'low risk' and classes III manual, IV, and $\mathrm{V}$, as 'high risk'.

(3) Place of residence. Of the centres collaborating in our studies, the highest birth prevalence of neural tube defect is in Northern Ireland, and residence here is indicative of 'high risk'.

(4) An excess of spontaneous abortions has been noted in the pregnancies immediately preceding births with neural tube defect. ${ }^{7-11} \mathrm{~A}$ spontaneous abortion immediately before a study pregnancy is therefore regarded as carrying a 'high risk'.

(5) The possibilty that an immediately prior therapeutic abortion conveys increased risk is also considered. 
(6) Clarke et al have postulated that residual trophoblast material from a previous pregnancy is important as a cause of neural tube defect. ${ }^{9}$ Although there is little information regarding survival of trophoblast material in vivo, it seems likely that the longer the interval between an abortion and the next conception the less likely is trophoblast material to remain. A fallow period of less than 12 months between an abortion and the beginning of the study pregnancy is therefore regarded as a possible risk factor.

\section{Materials and methods}

The data are from the combined first and second cohorts of mothers previously reported. ${ }^{1}$ All figures refer to infants/fetuses - that is, twins are counted as two outcomes. Exclusions are:

(a) All partially supplemented pregnancies.

(b) All cases where the outcome was an unexamıned spontaneous abortion (30 supplemented, 19 unsupplemented).

(c) Two supplemented and four unsupplemented women for whom information on immediately prior pregnancy was incomplete.

(d) For the analyses of social class only, all unclassified, unemployed, or unknown cases (13 supplemented and 44 unsupplemented, including two unsupplemented recurrences).

(e) For the analyses of fallow period, all cases where the immediately prior pregnancy did not end in a spontaneous or therapeutic abortion, or where the fallow period is unknown.

Firstly, each risk factor was considered separately. On the null hypothesis that vitamin supplementation has no effect on outcome, the relative risk due to each factor was calculated as:

Recurrences in all pregnancies (supplemented + unsupplemented) with that factor

Recurrences in all pregnancies (supplemented + unsupplemented) without that factor
The differential risk between supplemented and unsupplemented pregnancies due to that factor is then:

(\% Unsupplemented with factor $\times$ relative risk) $+\%$ unsupplemented without factor

$(\%$ Supplemented with factor $\times$ relative risk $)+\%$ supplemented without factor

Secondly, the contribution of factors individually or in combination was studied by multivariate analysis using a linear logistic model on the computer package GENSTATS. No distinction was made between spontaneous and therapeutic abortions in the immediately prior pregnancy, and fallow period was not considered. This analysis was performed on 795 outcomes where there were no missing data; these included all three recurrences in the supplemented group and 22 of 24 in the unsupplemented group.

\section{Results}

Table 1 shows the analysis of individual risk factors. Four factors ( $\geqslant$ two previous neural tube defects, residence in Ireland, immediately prior spontaneous abortion, and 12 months between abortion and study pregnancy) apparently lead to an increased risk. Only for two or more previous neural tube defects, however, is the increase significant, and when the distribution of the factors between the supplemented and unsupplemented groups is taken into account none of the factors leads to a predicted increase of more than $4 \%$ in the recurrence rate in the unsupplemented compared with the supplemented group (Table 1, right hand column).

In the multivariate analysis in Table 2 the effect of $\mathrm{n}$ factors is measured by the reduction in the deviance when they are introduced into the analysis. This reduction has a $\chi^{2}$ distribution with $\mathrm{n}$ degrees of freedom, and its significance can be found in $\chi^{2}$ tables. ${ }^{11}$ One factor ( $\geqslant$ two previous neural tube

Table 1 Effect of possible risk factors on differential risk of recurrence of neural tube defect in all (supplemented + unsupplemented) mothers

\begin{tabular}{|c|c|c|c|c|c|c|}
\hline \multirow[t]{2}{*}{ Factor } & \multicolumn{3}{|c|}{ Neural tube defect recurrences } & \multicolumn{2}{|c|}{ Pregnancies with factor } & \multirow{2}{*}{$\begin{array}{l}\text { Risk ratio due to factor } \\
\text { (unsupplemented: } \\
\text { supplemented) }\end{array}$} \\
\hline & $\begin{array}{l}\text { With } \\
\text { factor }\end{array}$ & $\begin{array}{l}\text { Without } \\
\text { factor }\end{array}$ & $\begin{array}{l}\text { Relative } \\
\text { risk }\end{array}$ & Supplemented & Unsupplemented & \\
\hline$\geqslant$ Two previous neural tube defects & $6 / 95$ & $21 / 836$ & $2 \cdot 51$ & $43 / 427$ & $52 / 504$ & $1 \cdot 0(0) 3$ \\
\hline Social class III manual, IV, and V & $15 / 537$ & $10 / 337$ & $(0.94$ & $226 / 414$ & $311 / 460$ & 0.992 \\
\hline Residence in Northern Ireland & $13 / 380$ & $14 / 551$ & $1 \cdot 35$ & $145 / 427$ & $235 / 504$ & $1 \cdot(040$ \\
\hline Immediately prior spontaneous abortion & $7 / 129$ & $20 / 8012$ & $2 \cdot 18$ & $52 / 427$ & $77 / 504$ & $1 \cdot 032$ \\
\hline Immediately prior therapeutic abortion & $2 / 79$ & $25 / 852$ & 0.86 & $53 / 427$ & $26 / 5() 4$ & $1 \cdot 010$ \\
\hline Fallow period <one year following abortion & $7 / 132$ & $1 / 65$ & $3 \cdot 45$ & $72 / 101$ & $60) / 96$ & 0.922 \\
\hline
\end{tabular}


Table 2 Multivariate analysis of risk factors (see text for explanation)

\begin{tabular}{|c|c|c|c|}
\hline Run & $\begin{array}{l}\text { Factors used } \\
\text { in regression }\end{array}$ & $\begin{array}{l}\text { Deviancel } \\
\text { degrees of } \\
\text { freedom }\end{array}$ & Comparison \\
\hline 1 & None & $38 \cdot 52 / 31$ & \\
\hline 2 & A & $34 \cdot 34 / 30$ & $2 v 1 \chi_{i}^{2}=4 \cdot 18 . \quad \mathrm{p}<0.05$ \\
\hline 3 & A. B & $34 \cdot 20 / 29$ & $3 v 2$ Not significant \\
\hline 4 & A. C & $34 \cdot 2(1 / 29$ & $4 \vee 2$ Not significant \\
\hline 5 & A. D & $33 \cdot(17 / 29$ & $5 \vee 2$ Not significant \\
\hline 6 & A. B. C. D & $32 \cdot 74 / 27$ & $6 \vee 2$ Not significant \\
\hline 7 & A. E & $19 \cdot 59 / 29$ & $7 v 2 \chi_{i}^{\dagger}=14 \cdot 75, p<0 \cdot(001$ \\
\hline 8 & All & $16 \cdot 67 / 26$ & $\begin{array}{l}8 \vee 7 \chi_{\overline{3}}^{\frac{3}{3}}=2 \cdot 92 . \text { Not significant } \\
8 \vee 6 \chi_{\overline{1}}^{2}=16 \cdot(07, \mathrm{p}<(0 .(0) 1\end{array}$ \\
\hline
\end{tabular}

Key to factors: $\mathrm{A}=\geqslant$ Two previous neural tube defects; $\mathrm{B}=$ Social class III manual. IV, and $\mathrm{V} ; \mathrm{C}=$ Residence in Northern Ireland; $\mathrm{D}=$ Immediately prior abortion (spontaneous or therapeutic); $\mathrm{E}=$ Vitamin supplementation.

defects) produces a significant reduction in the deviance (compare regression 2 with regression 1 ), but none of the other factors except vitamin supplementation has a significant effect. Immediately prior abortion, residence in Ireland, and social class jointly have no significant effect once the effect of having two or more previous neural tube defects is taken into account (compare regression 6 and 2). Vitamins have a highly significant effect either allowing just for two or more previous neural tube defects (regressions 7 and 2) or all other factors (regressions 8 and 6).

\section{Discussion}

After the publication of our trial of vitamin supplementation for the prevention of neural tube defect, ${ }^{1}$ several workers ${ }^{2-5}$ suggested that supplemented and unsupplemented mothers were at 'differential risk' for recurrence of neural tube defect. We have already responded to some of these criticisms. ${ }^{12} \quad 1.3$ Certainly, the difference between the recurrence rates for the supplemented and unsupplemented groups is too large and consistent between cohorts to be a chance effect; either vitamin supplementation reduces the risk of neural tube defect or the supplemented and unsupplemented groups differ about sevenfold in prior risk. Our results show that none of the factors considered here contributes any significant differential risk.

1 Number of previous neural tube defects. The well known increased risk of recurrence for mothers with two or more previous neural tube defects is seen in our data. Reports of our studies have always separated mothers with one previous neural tube defect from those with two or more, but Table 1 shows that the proportions are similar in the supplemented and unsupplemented groups, partly because of deliberate matching in some centres.

2 Social class. There is a well established relation between social class and occurrence of neural tube defect, but only one study (in Northern Ireland) has reported a similar relation between social class and recurrence of neural tube defect. ${ }^{6}$ In the present study the recurrence rate of neural tube defect is similar when comparison is made between classes I, II, and III non-manual $(3 \cdot 0 \%)$ and classes III manual, IV, and V $(2 \cdot 8 \%)$. Consequently, although there were proportionally more unsupplemented than supplemented women in the lower social class group, the unsupplemented:supplemented risk ratio in relation to social class is close to unity.

3 Area of residence. The higher occurrence of neural tube defect in Northern Ireland than in the rest of the United Kingdom is probably associated with a higher risk of recurrence, ${ }^{6}$ our data suggest a $35 \%$ higher risk if vitamins have no effect. The unsupplemented group contains rather more mothers from Northern Ireland than the supplemented, which leads to a predicted $4 \%$ increase in the recurrence rate in the unsupplemented group.

4 Immediately prior pregnancy ending in spontaneous abortion. Smithells et al noted that fetal death (spontaneous abortion plus stillbirth) was particularly common in pregnancies immediately before the birth of an anencephalic child. ${ }^{7}$ A similar excess of fetal deaths was found in pregnancies immediately before spina bifida. ${ }^{8}$ Clarke examined data from his own ${ }^{9}$ and other ${ }^{14} 15$ surveys of children affected by anencephaly or spina bifida. Considering only sibships in which at least one pregnancy had occurred both before and after the affected child, he found that there were always more spontaneous abortions plus stillbirths immediately before the affected child than immediately after. More recently, Cuckle has shown the increased frequency of a second neural tube defect in the pregnancy immediately after a spontaneous abortion in women with previous neural tube defect pregnancies. ${ }^{10}$

In our data the recurrence rate after a spontaneous abortion was $5.4 \%$ compared with $2.5 \%$ after all other outcomes, but this difference was not quite significant $(p=0 \cdot 06)$. In our unsupplemented women with one previous neural tube defect the association of neural tube defect with an immediately prior spontaneous abortion is similar to that found by Cuckle. ${ }^{10}$ The recurrence rate was $8 \cdot 8 \%$ after a spontaneous abortion compared with $3.4 \%$ after all other outcomes $(p=0 \cdot 05)$. The frequency of spontaneous abortion in the immediately prior 
pregnancy is similar, however, in the supplemented and unsupplemented groups, and the differential risk introduced is only $3 \%$.

\section{Immediately prior pregnancy ending in a therapeu-} tic abortion. This happened in $12.4 \%$ of supplemented but only $5 \cdot 2 \%$ of unsupplemented women. We have discussed before ${ }^{16}$ how our method of recruiting mothers for supplementation through genetic counselling clinics leads to an excess of women who have just had a neural tube defect pregnancy. Termination of the immediately prior pregnancy has not been considered before as a possible risk factor, and because of the imbalance between the supplemented and unsupplemented groups it could be important. Table 1 shows, however, that there is no increased risk of neural tube defect when the preceding pregnancy was terminated.

6 Length of fallow period. The excess of spontaneous abortions in the immediately prior pregnancy seems well established. Whether there is a causal connection is less clear. Knox first postulated that residual trophoblast was important in the aetiology of neural tube defect. ${ }^{17}$ Clarke suggested that the retention of trophoblast material is much more likely after a spontaneous abortion than after a normal delivery. ${ }^{9}$ There is little information about the survival of trophoblast in vivo. In vitro human trophoblast material taken from caesarian section at term has been successfully cultured for up to eight months, but a similar technique was not successful with early trophoblast. ${ }^{18}$ It seems likely that the longer the interval between the spontaneous abortion and the next conception the less likely is trophoblastic material to remain.

Table 1 shows that there is a threefold increase in the risk of recurrence in pregnancies started within 12 months of an abortion (spontaneous or therapeutic) compared with those with a prior abortion but a fallow period of a year or more. If confirmed, this would be the most powerful risk factor we have found, but the difference does not reach significance $(p=0 \cdot 2)$. Table 1 shows that this effect does not account for any of the difference in recurrence rate between our supplemented and unsupplemented groups. We have already reported that for all supplemented pregnancies the average time interval between conception and the end of the previous pregnancy was slightly shorter than for unsupplemented pregnancies. ${ }^{19}$

Most spontaneously aborted fetuses are not examined, and it is therefore possible that some of them have neural tube defects. In the obstetric histories studied by Clarke there is no indication whether aborted fetuses were examined. ${ }^{14}{ }^{15}$ Bell and Gosden examined over 500 unselected spontaneously aborted fetuses and found neural tube defect in $4.1 \%$ of them. ${ }^{20}$ In our study pregnancies roughly half the spontaneously aborted fetuses were examined; neural tube defect was found in $0 / 19$ examined fetuses of supplemented women and 1/25 of unsupplemented women. Although this small sample cannot be assumed to be representative, it suggests that the recurrence rate of neural tube defect among aborted fetuses may be similar to that in full term pregnancies. A small part of the increased recurrence of neural tube defect observed after a spontaneous abortion may therefore be attributable to previous but undetected neural tube defect. The effect of prior spontaneous abortion per se can only be determined by investigating recurrence rates of neural tube defect after spontaneous abortions that were examined and found to be unaffected.

Many questions will remain unanswered until more complete data on a very large number of women are available. It is clear, however, that the difference in recurrence rates of neural tube defect between vitamin supplemented and unsupplemented muthers cannot be attributed to any of the factors considered here, either alone or in combination. Indeed they cannot account for even a twofold difference in prior risk. On the differential risk hypothesis this is surprising: even if none of the factors considered here were the direct cause of the difference, all the likely nutritional, social, and obstetric variables should show some correlation. We cannot totally exclude the possibility that some 'invisible' factor influencing the risk of recurrence has segregated differentially as between supplemented and unsupplemented mothers. If, however, such a factor were causing a sevenfold difference the visible partially correlated factors might be expected to show some difference.

The method used here to look at individual factors may show some small apparent differential risk even if vitamins directly cause the whole of the difference observed. This is because any irrelevant factor that is randomly increased in the unsupplemented group may be scored as a positive risk factor (because most of the recurrences of neural tube defect are in the unsupplemented group), and this positive risk factor will by definition be increased in that group. Hence the small positive contributions by some factors to the risk ratio are not evidence that if a sufficient number of such factors were considered then the whole differential risk could be explained. Further statistical analysis of our vitamin supplementation trial therefore 
suggests that the highly significant difference in recurrence rates of neural tube defect between supplemented and unsupplemented mothers was not attributable to differential risks between the two groups but to some aspect of vitamin supplementation. It is possible, however, that factors associated with the taking of vitamin tablets-for example, subtle preconceptional changes of life style-may have contributed to the reduced recurrence rate of neural tube defect. It remains true that periconceptional vitamin supplementation is associated with a significantly reduced rate.

We thank Linda Hunt for advice on GENSTATS and Beecham Pharmaceuticals for supplying Pregnavite Forte F. Jennifer Wild was supported by Action Research for the Crippled Child.

\section{References}

' Smithells RW, Nevin NC. Seller MJ, et al. Further experience of vitamin supplementation for prevention of neural tube recurrences. Lancet 1983:i:1(1)27-31.

2 Knox EG. Vitamin supplementation and neural tube defects Lancet 1983:ii:39.

${ }^{3}$ Oakley GP Jr. Adams MJ Jr, James LM. Vitamins and neural tube defects. Lancet 1983;ii:798-9.

4 Elwood JM. Can vitamins prevent neural tube defects?' ('an Med Assoc J 1983:129:1088-92.

5 Wald NJ, Polani PE. Neural-tube defects and vitamins: the need for a randomized clinical trial. Br J Obstet Gvnaecol 1984:91:516-23.

"Nevin NC. Johnston WP. Merrett JD. Influence of social class on the risk of recurrence of anencephalus and spina bifida. Dev Med Child Neurol 1981;23:155-9.

7 Smithells RW, Chinn ER, Franklin D. Anencephaly in Liverpool. Dev Med Child Neurol 1964:6:231-40.
× Smithells RW, Chinn ER. Spina bifida in Liverpool. Dev Med Child Neurol 1965:7:258-68.

" Clarke CA. Hobson D. McKendrick OM. et al. Spina bifida and anencephaly: miscarriage as possible cause. $\mathrm{Br}$ Med J 1975:iv:743-6.

1" Cuckle HS. Recurrence risk of neural tube defects following a miscarriage. Prenat Diagn 1983:3:287-9.

11 Williams K. Analysis of multidimensional contingency tables. The Statistician 1976:25:51-8.

'2 Smithells RW. Can vitamins prevent neural tube defects? Can Med Assoc J 1984:131:273-5.

1. Smithells RW. Sheppard S. Wild J. et al. Neural tube defects and vitamins: the need for a randomized clinical trial. $\mathrm{Br} J$ Obstet Gynaecol 1985;92:185-9.

it Carter CO. David PA. Laurence KM. A family study of eentral nervous system malformations in South Wales. J Med Genet 1968:5:81-106.

15 Williamson EM. Incidence and family aggregation of major congenital malformations of eentral nervous svstem. J Med Genet 1965:2:161-72.

1" Smithells RW. Sheppard S. Schorah CJ, et al. Apparent prevention of neural tube defects by periconceptional vitamin supplementation. Arch D)is ('hild 1981:56:911-8.

${ }^{17}$ Knox EG. Twins and neural tube defects. British Journal of Preventive and Social Medicine 1974:28:73-80.

Ix Aladjem S, Lueck J. Morphologic characteristics of the normal term human trophoblast maintained in prolonged in vitro cultures. Brit J Obstet Gynaecol 1981;88:287-93.

19 Smithells RW, Seller MJ, Harris R, et al. Vitamin supplementation and neural tube defects. Lancet 1983;ii:40.

20 Bell JE, Gosden CM. Central nervous system abnormalities contrasting patterns in early and late pregnancy. Clin Genet 1978;13:387-96.

Correspondence to Professor R W Smithells, University Department of Pacdiatrics and Child Health, D Floor, Clarendon Wing, The General Infirmary at Leeds, Belmont Grove, Leeds LS2 9NS, England.

Received 25 February 1986 